\title{
A New Unified Solution for Deep Tunnels in Water-Rich Areas considering Pore Water Pressure
}

\author{
Hao Fan $(\mathbb{D}$, Lianguo Wang $(\mathbb{D}$, Shuai Wang $(\mathbb{D}$, and Chongyang Jiang $(\mathbb{D}$ \\ State Key Laboratory for Geomechanics and Deep Underground Engineering, China University of Mining and Technology, \\ Xuzhou 221116, China \\ Correspondence should be addressed to Lianguo Wang; cumt_lgwang@163.com
}

Received 26 December 2020; Revised 24 January 2021; Accepted 28 January 2021; Published 20 February 2021

Academic Editor: Yi Xue

Copyright ( 2021 Hao Fan et al. This is an open access article distributed under the Creative Commons Attribution License, which permits unrestricted use, distribution, and reproduction in any medium, provided the original work is properly cited.

\begin{abstract}
Pore water pressure has an important influence on the stresses and deformation of the surrounding rock of deep tunnels in waterrich areas. In this study, a mechanical model for deep tunnels subjected to a nonuniform stress field in water-rich areas is developed. Considering the pore water pressure, a new unified solution for the stresses, postpeak zone radii, and surface displacement is derived based on a strain-softening model and the Mogi-Coulomb criterion. Through a case study, the effects of pore water pressure, intermediate principal stress, and residual cohesion on the stress distribution, postpeak zone radii, and surface displacement are also discussed. Results show that the tangential stresses are always larger than the radial stress. The radial stress presents a gradually increasing trend, while the tangential stress presents a trend of first increasing and then decreasing, and the maximum tangential stress appears at the interface between the elastic and plastic zones. As the pore water pressure increases, the postpeak zone radii and surface displacement increase. Because of the neglect of the intermediate principal stress in the Mohr-Coulomb criterion, the postpeak zone radii, surface displacement, and maximum tangential stress solved by the Mohr-Coulomb criterion are all larger than those solved by the Mogi-Coulomb criterion. Tunnels surrounded by rock masses with a higher residual cohesion experience lower postpeak zone radii and surface displacement. Data presented in this study provide an important theoretical basis for supporting the tunnels in water-rich areas.
\end{abstract}

\section{Introduction}

Tunnels are one of the most basic facilities in water conservancy engineering, civil engineering, and mining engineering $[1-3]$. The stress distribution of the rock mass changes with the excavation of the tunnel, and the surrounding rock of the tunnel will be deformed if the redistributed stress exceeds the peak strength of the rock mass. Therefore, accurate calculation for the stress of the surrounding rock plays an important role in stability evaluation and support design of the tunnel [4-6].

In the past decades, a series of unified solutions based on different strength criteria have been proposed. Some common strength criteria, such as the Mohr-Coulomb criterion [7-10] and the Hoek-Brown criterion [11-14], were widely used to calculate the stress in the tunnel surrounding rock.
However, the intermediate principal stress is not considered in these criteria, which caused an inaccurate result. In fact, the surrounding rock of the tunnel is always in a true triaxial stress environment $[15,16]$, and the intermediate principal stress has a nonnegligible influence on the strength of the rock mass. Therefore, it is of great significance that the intermediate principal stress be taken into consideration in the unified solution for deep tunnels.

Because of the underground faults, folds, and other special structures, the ratio of the vertical stress to horizontal stress is usually not equal to one. In this case, Galin [17] first analyzed the tunnel in a nonuniform stress field and deduced the radius of the plastic zone. However, Galin's solution only applies to frictionless rock mass. Detournay [18-20] extended Galin's result to other materials and obtained the boundary of the elastic and plastic zones. Tokar [21], 
Leitman and Villaggio [22], and Ochensberger et al. [23] also presented a series of analytical solutions for a circular wellbore in some certain cases based on Galin's solution.

It is known that the flowing water always exists in the underground rock mass, which has a certain impact on the stress distribution and deformation of the surrounding rock of the tunnel. Therefore, the influence of the pore water pressure should be considered in the elastic-plastic analysis for deep tunnels in water-rich areas [24-26]. In the present study, a mechanical model for deep tunnels subjected to a nonuniform stress field in water-rich areas is first established. Considering the pore water pressure, a new unified solution for the stresses, postpeak zone radii, and surface displacement is derived based on strain-softening model and MogiCoulomb criterion. Through a case study, the sensitivity of pore water pressure, intermediate principal stress, and residual cohesion on the stress distribution, postpeak zone radii, and surface displacement is analyzed.

\section{Definition of the Problem}

2.1. Mechanical Model of a Circular Tunnel. A circular tunnel of radius $R_{0}$ was excavated in an infinite rock mass (Figure 1). The vertical and horizontal stresses are $\sigma_{0}$ and $\lambda \sigma_{0}$, respectively, where $\lambda$ is the lateral stress coefficient. A support pressure $\left(P_{i}\right)$ is uniformly distributed along the excavation surface. The surrounding rock of the tunnel is subdivided into an elastic zone (" $e$ "), plastic zone (" $p$ "), and damage zone (" $d$ "). The radii of the elastic, plastic, and damage zones are denoted by $R_{e}, R_{p}$, and $R_{d}$, respectively.

We assume that there is a pore water pressure $\left(P_{0}\right)$ outside the elastic zone of the tunnel. Based on Darcy's law, the continuous differential equation of seepage is

$$
\frac{\mathrm{d}^{2} P_{w}}{\mathrm{~d} r^{2}}+\frac{1}{r} \frac{\mathrm{d} P_{w}}{\mathrm{~d} r}=0
$$

where $P_{w}$ is the pore water pressure at any point of the tunnel surrounding rocks.

Combined with the boundary condition of $P_{w}=0$ at $r=$ $R_{0}$ and $P_{w}=P_{0}$ at $r=R_{e}$, the pore water pressure can be derived by solving Equation (1):

$$
P_{w}=P_{0} \frac{\ln \left(R_{0} / r\right)}{\ln \left(R_{0} / R_{e}\right)} .
$$

2.2. Strain-Softening Model. As shown in Figure 2, the experimental stress-strain curve of the rock mass can be simplified into a three-section line. The three straight lines correspond to the elastic zone, plastic zone, and damage zone, respectively.

\section{Analytical Solution}

3.1. Basic Equations. The Mogi-Coulomb criterion can be expressed as [27-29]

$$
\sigma_{\theta i}=M \sigma_{r i}+N_{i},
$$

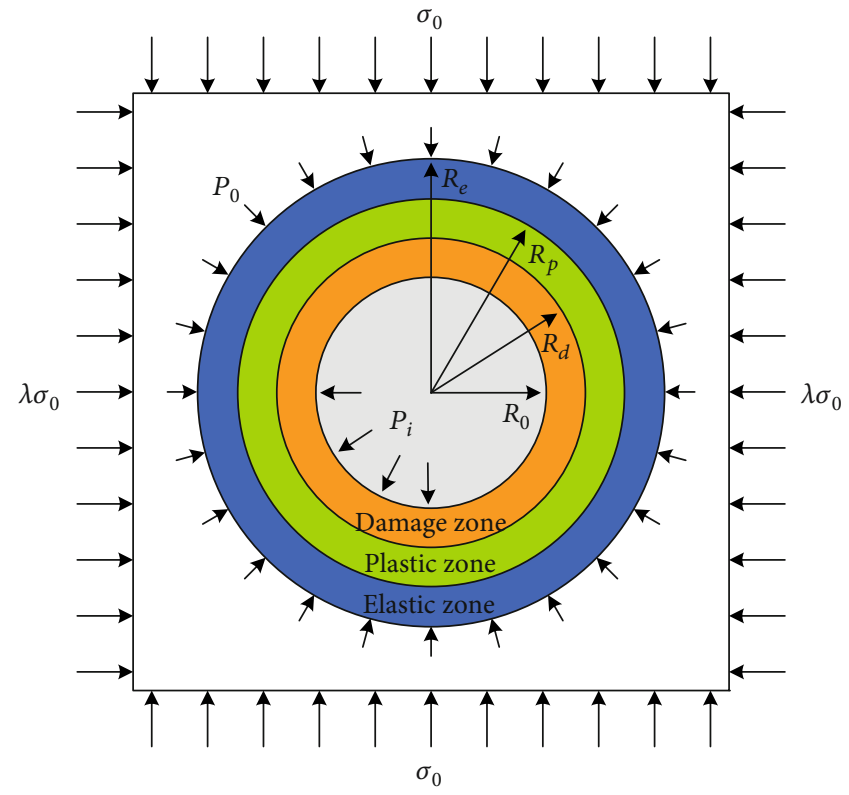

FIgURE 1: Mechanical model of tunnels subjected to a nonuniform stress field in water-rich area.

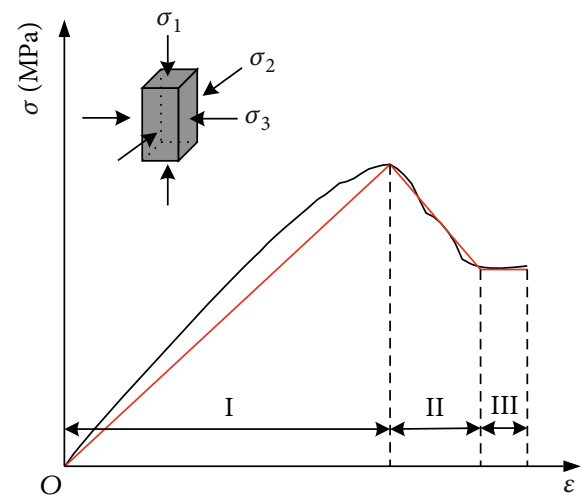

$$
\begin{aligned}
& \text { I : Elastic zone } \\
& \text { II : Plastic zone } \\
& \text { III : Damage zone } \\
& \text { _ Experimental curve } \\
& \text { _ Simplified curve }
\end{aligned}
$$

FIgURE 2: Total stress-strain curve of rock mass.

where $\sigma_{\theta i}$ and $\sigma_{r i}$ are the tangential and radial stresses in the “i” region, respectively; $M=(\sqrt{3}+2 \sin \varphi) /(\sqrt{3}-2 \sin \varphi) ; \varphi$ is the internal friction angle; $N_{i}=4 c_{i} \cos \varphi /(\sqrt{3}-2 \sin \varphi)$; and $c_{i}$ represents the cohesion in different zones. The symbol " $i$ " can be replaced by " $e$," " $p$," and " $d . "$

Taking the pore water pressure into consideration, the equilibrium differential equation in the " $i$ " zone can be given as

$$
\frac{\mathrm{d} \sigma_{r i}}{\mathrm{~d} r}+\frac{\sigma_{r i}-\sigma_{\theta i}}{r}+\eta \frac{\mathrm{d} P_{w}}{\mathrm{~d} r}=0,
$$

where $\eta$ is the pore water pressure coefficient. 


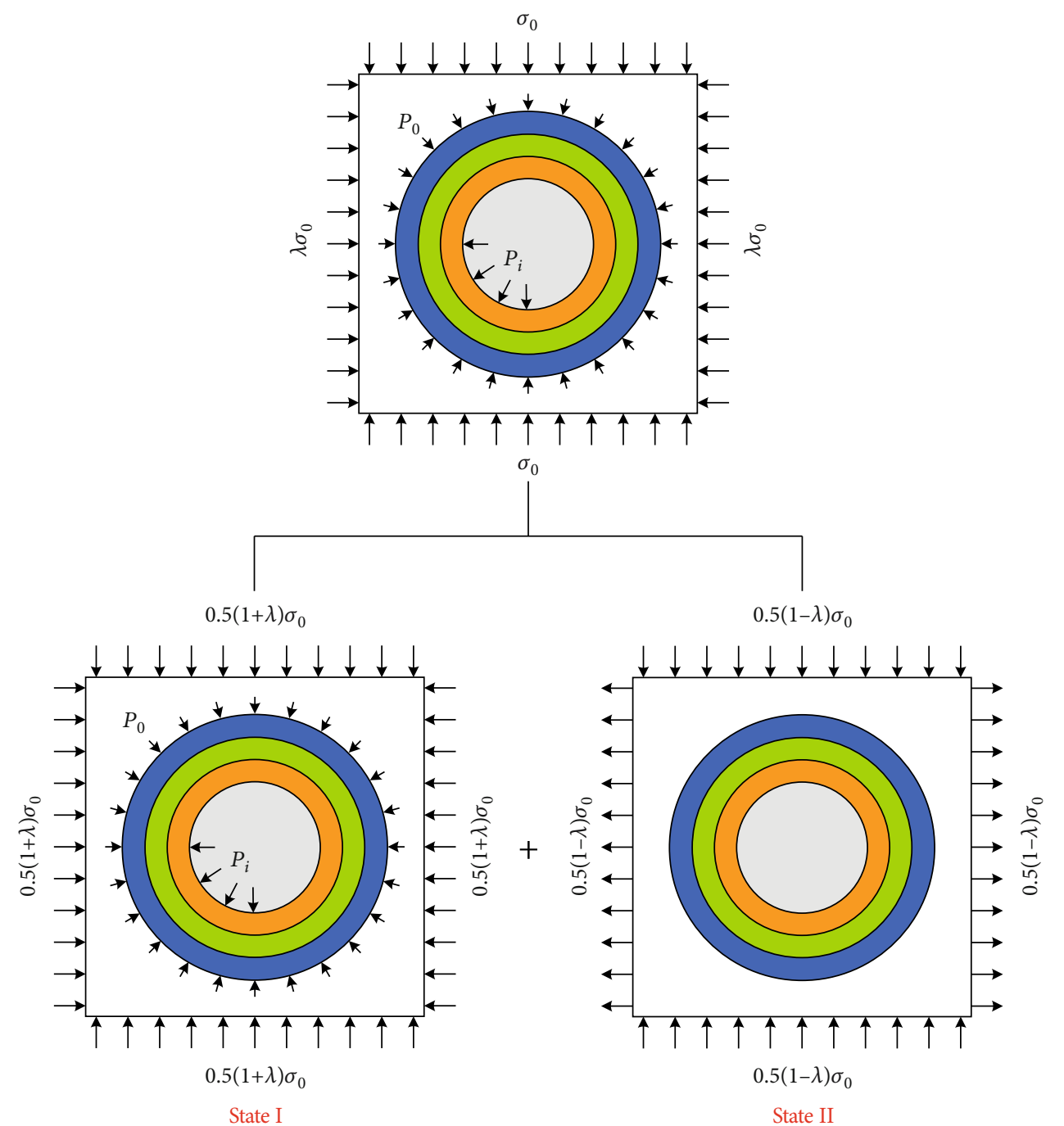

FIGURE 3: Mechanical model of surrounding rock in water-rich coal tunnel.

The geometric equation can be written as

$$
\left\{\begin{array}{l}
\varepsilon_{r i}=\frac{\mathrm{d} u_{i}}{\mathrm{~d} r} \\
\varepsilon_{\theta i}=\frac{u_{i}}{r},
\end{array}\right.
$$

where $\varepsilon_{r i}$ and $\varepsilon_{\theta i}$ are the radial and tangential strains in the " $i$ " zone, respectively, and $u_{i}$ represents the displacement in the " $i$ " zone.

The constitutive equations can be denoted as

$$
\left\{\begin{array}{l}
\varepsilon_{r}=\frac{1-\mu^{2}}{E}\left(\sigma_{r}-\frac{\mu}{1-\mu} \sigma_{\theta}\right), \\
\varepsilon_{\theta}=\frac{1-\mu^{2}}{E}\left(\sigma_{\theta}-\frac{\mu}{1-\mu} \sigma_{r}\right)
\end{array}\right.
$$

where $\mu$ and $E$ are Poisson's ratio and Young's modulus of the rock mass, respectively.
In addition, the volume of the rock mass is always changing in the postpeak failure zone; the plastic-strain relationships can be developed based on the nonassociated flow rule as follows:

$$
\varepsilon_{r i}+\beta_{i} \varepsilon_{\theta i}=0
$$

where $\beta_{i}=\left(1+\sin \psi_{i}\right) /\left(1-\sin \psi_{i}\right) ; \psi_{i}$ is the dilation angle in the " $i$ " zone.

3.2. Elastic Zone. The stress state of the circular tunnel in a nonuniform stress field can be decomposed into two parts (see Figure 3). In state I, the tunnel is subjected to a uniform pressure $\left(0.5(1+\lambda) \sigma_{0}\right)$, pore water pressure $\left(P_{w}\right)$, and support pressure $\left(P_{i}\right)$; the differential equation can be obtained by substituting Equations (2), (5), and (6) into Equation (3):

$$
\frac{\mathrm{d}^{2} u_{e 1}}{\mathrm{~d} r^{2}}+\frac{1}{r} \frac{\mathrm{d} u_{e 1}}{\mathrm{~d} r}-\frac{u_{e 1}}{r^{2}}=\frac{F v}{r E},
$$

where $F=\eta P_{0} / \ln \left(R_{0} / R_{e}\right)$ and $v=(1+\mu)(1-2 \mu) /(1-\mu)$. 
Solving Equation (8), the displacement and strains in state I can be easily obtained as

$$
\left\{\begin{array}{l}
u_{e 1}=C_{1} r+\frac{C_{2}}{r}+\frac{F v r \ln r}{2 E}, \\
\varepsilon_{r e 1}=C_{1}-\frac{C_{2}}{r^{2}}+\frac{F v}{2 E}(\ln r+1), \\
\varepsilon_{\theta e 1}=C_{1}+\frac{C_{2}}{r^{2}}+\frac{F v \ln r}{2 E}
\end{array}\right.
$$

where $C_{1}$ and $C_{2}$ are integral constants.

The radial and tangential stresses can be derived by integrating Equations (6) and (9):

$$
\left\{\begin{array}{l}
\sigma_{r e 1}=\frac{E C_{1}}{(1+\mu)(1-2 \mu)}-\frac{E C_{2}}{(1+\mu) r^{2}}+\frac{\eta F \ln r}{2(1-\mu)}+\frac{\eta F}{2} \\
\sigma_{\theta e 1}=\frac{E C_{1}}{(1+\mu)(1-2 \mu)}+\frac{E C_{2}}{(1+\mu) r^{2}}+\frac{\eta F \ln r}{2(1-\mu)}+\frac{\mu \eta F}{2(1-\mu)}
\end{array}\right.
$$

Considering the boundary condition $\sigma_{r}=0.5(1+\lambda) \sigma_{0}$ $+P_{0}$ at $r=R_{0}$ and $\sigma_{r}=\sigma_{r}^{e-p}$ at $r=R_{p}$, the integral constants can be solved as follows:

$$
\begin{aligned}
C_{1}= & \frac{v(1-\mu)}{E}\left[\frac{1}{2}(1+\lambda) \sigma_{0}+P_{0}\right] \\
& +\frac{R_{p}^{2}}{R_{e}{ }^{2}-R_{p}^{2}} \frac{v(1-\mu)}{E}\left[\frac{1}{2}(1+\lambda) \sigma_{0}+P_{0}-\sigma_{r}^{e-p}\right] \\
& +\frac{\eta F v}{2 E} \frac{R_{p}^{2}}{R_{e}{ }^{2}-R_{p}^{2}} \ln \frac{R_{p}}{R_{e}}-\frac{\eta F v(1-\mu)}{2 E}-\frac{\eta F v}{2 E} \ln R_{e}, \\
C_{2}= & \frac{1+\mu}{E} \frac{R_{e}^{2} R_{p}^{2}}{R_{e}{ }^{2}-R_{p}{ }^{2}}\left[\frac{1}{2}(1+\lambda) \sigma_{0}+P_{0}-\sigma_{r}^{e-p}\right] \\
& +\frac{\eta F(1+\mu)}{2 E(1-\mu)} \frac{R_{e}{ }^{2} R_{p}{ }^{2}}{R_{e}{ }^{2}-R_{p}^{2}} \ln \frac{R_{p}}{R_{e}} .
\end{aligned}
$$

The stresses in state I can be determined by substituting Equation (11) into Equation (10):

$$
\left\{\begin{array}{l}
\sigma_{r e 1}=\frac{1}{2}(1+\lambda) \sigma_{0}+P_{0}+\frac{\eta F}{2(1-\mu)} \ln \frac{r}{R_{e}}+\frac{R_{p}{ }^{2}}{R_{p}{ }^{2}-R_{e}{ }^{2}}\left(\frac{R_{e}{ }^{2}}{r^{2}}-1\right), \\
{\left[\frac{1}{2}(1+\lambda) \sigma_{0}+P_{0}-\sigma_{r}^{e-p}+\frac{\eta F}{2(1-\mu)} \ln \frac{R_{p}}{R_{e}}\right],} \\
\sigma_{\theta e 1}=\frac{1}{2}(1+\lambda) \sigma_{0}+P_{0}+\frac{\eta F}{2} \frac{\ln \left(r / R_{e}\right)+2 \mu-1}{1-\mu}-\frac{R_{p}^{2}}{R_{p}^{2}-R_{e}{ }^{2}}\left(\frac{R_{e}{ }^{2}}{r^{2}}+1\right), \\
{\left[\frac{1}{2}(1+\lambda) \sigma_{0}+P_{0}-\sigma_{r}^{e-p}+\frac{\eta F}{2(1-\mu)} \ln \frac{R_{p}}{R_{e}}\right] .}
\end{array}\right.
$$

In state II, the surrounding rock is subjected to a horizontal tension $\left(0.5(1-\lambda) \sigma_{0}\right)$ and a vertical pressure $\left(0.5(1-\lambda) \sigma_{0}\right)$. At $r=R_{s}$, the boundary condition can be written as follows:

$$
\left\{\begin{array}{l}
\sigma_{x}=-0.5(1-\lambda) \sigma_{0} \\
\sigma_{y}=0.5(1-\lambda) \sigma_{0} \\
\tau_{r \theta}=0
\end{array}\right.
$$

Though coordinate transformation, Equation (13) can be re written as follows:

$$
\left\{\begin{array}{l}
\sigma_{r}=-0.5(1-\lambda) \sigma_{0} \cos 2 \theta \\
\tau_{r \theta}=0.5(1-\lambda) \sigma_{0} \sin 2 \theta
\end{array}\right.
$$

At $r=R_{0}, \sigma_{x}=\tau_{r \theta}=0$. Therefore, using semi-inverse method, the stresses in state II can be deduced as follows:

$$
\left\{\begin{array}{l}
\sigma_{r e 2}=-\frac{1}{2}(1-\lambda) \sigma_{0}\left(1-4 \frac{R_{p}{ }^{2}}{r^{2}}+3 \frac{R_{p}{ }^{4}}{r^{4}}\right) \cos 2 \theta \\
\sigma_{\theta e 2}=\frac{1}{2}(1-\lambda) \sigma_{0}\left(1+3 \frac{R_{p}^{4}}{R^{4}}\right) \cos 2 \theta
\end{array}\right.
$$

Therefore, the stresses in the elastic zone considering pore water pressure can be obtained by superimposing Equations (12) and (15):

$$
\begin{aligned}
\sigma_{r e}= & \frac{1}{2}(1+\lambda) \sigma_{0}+P_{0}+\frac{\eta F}{2(1-\mu)} \ln \frac{r}{R_{e}}+\frac{R_{p}{ }^{2}}{R_{p}{ }^{2}-R_{e}{ }^{2}}\left(\frac{R_{e}{ }^{2}}{r^{2}}-1\right) \\
& \cdot\left[\frac{1}{2}(1+\lambda) \sigma_{0}+P_{0}-\sigma_{r}^{e-p}+\frac{\eta F}{2(1-\mu)} \ln \frac{R_{p}}{R_{e}}\right] \\
& -\frac{1}{2}(1-\lambda) \sigma_{0}\left(1-4 \frac{R_{p}^{2}}{r^{2}}+3 \frac{R_{p}^{4}}{r^{4}}\right) \cos 2 \theta, \\
\sigma_{\theta e}= & \frac{1}{2}(1+\lambda) \sigma_{0}+P_{0}+\frac{\eta F \ln \left(r / R_{e}\right)+2 \mu-1}{1-\mu}-\frac{R_{p}{ }^{2}}{R_{p}{ }^{2}-R_{e}{ }^{2}}\left(\frac{R_{e}{ }^{2}}{r^{2}}+1\right) \\
& \cdot\left[\frac{1}{2}(1+\lambda) \sigma_{0}+P_{0}-\sigma_{r}^{e-p}+\frac{\eta F}{2(1-\mu)} \ln \frac{R_{p}}{R_{e}}\right] \\
& +\frac{1}{2}(1-\lambda) \sigma_{0}\left(1+3 \frac{R_{p}^{4}}{r^{4}}\right) \cos 2 \theta .
\end{aligned}
$$

At the interface between the elastic and plastic zones, the radial and tangential stresses should satisfy Equation (3). Thus, $\sigma_{r}^{e-p}$ can be derived by substituting Equation (16) into Equation (3): 


$$
\sigma_{r}^{e-p}=\frac{\left\{-2 R_{e}^{2}\left[(1 / 2)(1+\lambda) \sigma_{0}+P_{0}\right]+\eta F / 2(1-\mu)\left[\left(R_{p}^{2}-R_{e}^{2}\right)\left(\ln \left(R_{p} / R_{e}\right)+2 \mu-1\right)-\left(R_{p}{ }^{2}+R_{e}^{2}\right) \ln \left(R_{p} / R_{e}\right)\right]+2(1-\lambda) \sigma_{0} \cos 2 \theta\left(R_{p}{ }^{2}-R_{e}^{2}\right)-N_{e}\left(R_{p}^{2}-R_{e}{ }^{2}\right)\right\}}{\left[M\left(R_{p}{ }^{2}-R_{e}{ }^{2}\right)-R_{p}{ }^{2}-R_{e}{ }^{2}\right]} .
$$

The radial and tangential strains in the elastic zone can be derived by substituting Equation (14) into Equation (6):

$$
\left\{\begin{array}{l}
\varepsilon_{r e}=C_{1}-\frac{C_{2}}{r^{2}}+\frac{\eta F v}{2 E}(\ln r+1)-\frac{1+\mu}{2 E}(1-\lambda) \sigma_{0}\left[1-4(1-\mu) \frac{R_{p}{ }^{2}}{r^{2}}+3 \frac{R_{p}{ }^{4}}{r^{4}}\right] \cos 2 \theta, \\
\varepsilon_{\theta e}=C_{1}+\frac{C_{2}}{r^{2}}+\frac{\eta F v \ln r}{2 E}+\frac{1+\mu}{2 E}(1-\lambda) \sigma_{0}\left(1-4 \mu \frac{R_{p}^{2}}{r^{2}}+3 \frac{R_{p}^{4}}{r^{4}}\right) \cos 2 \theta .
\end{array}\right.
$$

Using Equation (5), the displacement in the elastic zone can be easily obtained as

$$
\begin{aligned}
u_{e}= & C_{1} r+\frac{C_{2}}{r}+\frac{\eta F v r \ln r}{2 E}+\frac{1+\mu}{2 E}(1-\lambda) \sigma_{0} \\
& \cdot\left(r-4 \mu \frac{R_{p}{ }^{2}}{r}+3 \frac{R_{p}{ }^{4}}{r^{3}}\right) \cos 2 \theta .
\end{aligned}
$$

3.3. Plastic Zone. In the plastic zone, the total strain of the surrounding rock consists of two parts: the plastic and the elastic part. Thus, the following equation can be easily given as

$$
\left\{\begin{array}{l}
\varepsilon_{r}=\varepsilon_{r p}+\varepsilon_{r}^{e-p} \\
\varepsilon_{\theta}=\varepsilon_{\theta p}+\varepsilon_{\theta}^{e-p}
\end{array}\right.
$$

The displacement differential equation in the plastic zone can be obtained by integrating Equations (5), (7), and (20):

$$
\frac{\mathrm{d} u_{p}}{\mathrm{~d} r}+\beta_{p} \frac{u_{p}}{r}=\varepsilon_{r}^{e-p}+\beta_{p} \varepsilon_{\theta}^{e-p} .
$$

With the boundary condition of $u_{p}=u^{e-p}$ at $r=R_{p}$, the displacement in the plastic zone can be deduced by solving Equation (21):

$$
u_{p}=\left[\frac{u^{e-p}-\varepsilon_{r}^{e-p} R_{p}}{\beta_{p}+1}\right]\left(\frac{R_{p}}{r}\right)^{\beta_{p}}+\frac{\left(\varepsilon_{r}^{e-p}+\beta_{p} \varepsilon_{\theta}^{e-p}\right) r}{\beta_{p}+1} .
$$

Using Equation (5), the strains in the plastic zone can be obtained as

$$
\left\{\begin{array}{l}
\varepsilon_{r p}=\frac{\beta_{p}\left(\varepsilon_{r}^{e-p}-\varepsilon_{\theta}^{e-p}\right)}{\beta_{p}+1}\left(\frac{R_{p}}{r}\right)^{\beta_{p}+1}+\frac{\varepsilon_{r}^{e-p}+\beta_{p} \varepsilon_{\theta}^{e-p}}{\beta_{p}+1} \\
\varepsilon_{\theta p}=\frac{\varepsilon_{\theta}^{e-p}-\varepsilon_{r}^{e-p}}{\beta_{p}+1}\left(\frac{R_{p}}{r}\right)^{\beta_{p}+1}+\frac{\varepsilon_{r}^{e-p}+\beta_{p} \varepsilon_{\theta}^{e-p}}{\beta_{p}+1}
\end{array}\right.
$$

Previous studies indicated that the internal friction angle of the rock does not change significantly in the postpeak phase, and the rock strength is only related to cohesion. Assuming that the cohesion in the plastic zone decreases linearly (see Figure 4), the cohesion at any point in the plastic zone can be expressed as

$$
\begin{aligned}
c_{p} & =c_{0}-\alpha\left(\varepsilon_{\theta p}-\varepsilon_{\theta}^{e-p}\right) \\
& =c_{0}-\alpha\left[\frac{\varepsilon_{\theta}^{e-p}-\varepsilon_{r}^{e-p}}{\beta_{p}+1}\left(\frac{R_{p}}{r}\right)^{\beta_{p}+1}+\frac{\varepsilon_{r}^{e-p}+\beta_{p} \varepsilon_{\theta}^{e-p}}{\beta_{p}+1}-\varepsilon_{\theta}^{e-p}\right] \\
& =c_{0}-\frac{\alpha\left(\varepsilon_{\theta}^{e-p}-\varepsilon_{r}^{e-p}\right)}{\beta_{p}+1}\left[\left(\frac{R_{p}}{r}\right)^{\beta_{p}+1}-1\right]
\end{aligned}
$$

where $c_{0}$ is the initial cohesion and $\alpha$ is the softening coefficient of the cohesion. 


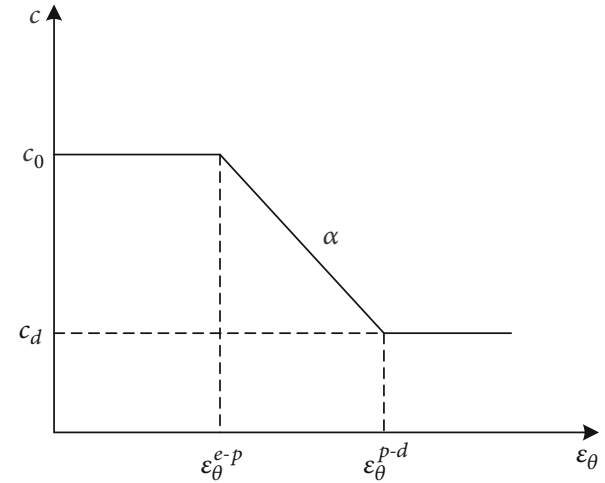

Figure 4: Softening model of the cohesion.

The equilibrium differential equation in the plastic zone can be rewritten by substituting Equations (2), (3), and (24) into Equation (4).

$$
\begin{aligned}
\frac{\mathrm{d} \sigma_{r}}{\mathrm{~d} r}+ & \frac{(1-M) \sigma_{r}}{r}-\frac{4 \cos \varphi}{(\sqrt{3}-2 \sin \varphi)} \\
& \cdot \frac{\left\{c_{0}-\alpha\left(\varepsilon_{\theta}^{e-p}-\varepsilon_{r}^{e-p}\right) /\left(\beta_{p}+1\right)\left[\left(R_{p} / r\right)^{\beta_{p}+1}-1\right]\right\}}{r} \\
& -\frac{\eta F}{r}=0
\end{aligned}
$$

Combining the boundary condition of $\sigma_{r}=\sigma_{r}^{e-p}$ at $r=$ $R_{p}$, the radial stress in the plastic zone can be obtained by solving Equation (25) as

$$
\begin{aligned}
\sigma_{r p}= & \left(\sigma_{r}^{e-p}-\frac{N_{e}+\eta F}{1-M}\right)\left(\frac{R_{p}}{r}\right)^{1-M} \\
& +\frac{4 \cos \varphi /(\sqrt{3}-2 \sin \varphi) \alpha\left(\varepsilon_{\theta}^{e-p}-\varepsilon_{r}^{e-p}\right)}{\left(\beta_{p}+1\right)\left(\beta_{p}+M\right)} \\
& \cdot\left[\left(\frac{R_{p}}{r}\right)^{1+\beta_{p}}-\left(\frac{R_{p}}{r}\right)^{1-M}\right] \\
& +\frac{4 \cos \varphi /(\sqrt{3}-2 \sin \varphi) \alpha\left(\varepsilon_{\theta}^{e-p}-\varepsilon_{r}^{e-p}\right)}{\left(\beta_{p}+1\right)(1-M)} \\
& \cdot\left[1-\left(\frac{R_{p}}{r}\right)^{1-M}\right]+\frac{N_{e}+\eta F}{1-M} .
\end{aligned}
$$

3.4. Damage Zone. In the damage zone, the total strains of the surrounding rock are also composed of two parts as:

$$
\left\{\begin{array}{l}
\varepsilon_{r}=\varepsilon_{r d}+\varepsilon_{r}^{p-d} \\
\varepsilon_{\theta}=\varepsilon_{\theta d}+\varepsilon_{\theta}^{p-d}
\end{array}\right.
$$

where $\varepsilon_{r}^{p-d}$ and $\varepsilon_{\theta}{ }^{p-d}$ are the radial and tangential strains at the interface between the plastic and damage zones, respectively.

The displacement differential equation in the plastic zone can be obtained by integrating Equations (5), (7), and (27):

$$
\frac{\mathrm{d} u_{d}}{\mathrm{~d} r}+\beta_{d} \frac{u_{d}}{r}=\varepsilon_{r}^{p-d}+\beta_{d} \varepsilon_{\theta}^{p-d} .
$$

Considering the boundary condition of $u_{d}=u^{p-d}$ at $r=$ $R_{d}$, the displacement in the plastic zone can be deduced by solving Equation (28):

$$
u_{d}=\left[\frac{u^{p-d}-\varepsilon_{r}^{p-d} R_{d}}{\beta_{d}+1}\right]\left(\frac{R_{d}}{r}\right)^{\beta_{d}}+\frac{\left(\varepsilon_{r}^{p-d}+\beta_{d} \varepsilon_{\theta}^{p-d}\right) r}{\beta_{d}+1} .
$$

Using Equation (5), the strains in the damage zone can be achieved as follows:

$$
\left\{\begin{array}{l}
\varepsilon_{r d}=\frac{\beta_{d}\left(\varepsilon_{r}^{p-d}-\varepsilon_{\theta}^{p-d}\right)}{\beta_{p}+1}\left(\frac{R_{d}}{r}\right)^{\beta_{p}+1}+\frac{\varepsilon_{r}^{p-d}+\beta_{d} \varepsilon_{\theta}^{p-d}}{\beta_{d}+1}, \\
\varepsilon_{\theta d}=\frac{\varepsilon_{\theta}^{p-d}-\varepsilon_{r}^{p-d}}{\beta_{d}+1}\left(\frac{R_{d}}{r}\right)^{\beta_{d}+1}+\frac{\varepsilon_{r}^{p-d}+\beta_{d} \varepsilon_{\theta}^{p-d}}{\beta_{d}+1} .
\end{array}\right.
$$

The equilibrium differential equation in the damage zone can be rewritten by substituting Equations (2) and (3) into Equation (4) as

$$
\frac{\mathrm{d} \sigma_{r}}{\mathrm{~d} r}+\frac{(1-M) \sigma_{r}-N_{d}}{r}-\frac{\eta F}{r}=0 .
$$

Combining the boundary condition of $\sigma_{r}=P_{i}$ at $r=R_{0}$, the radial stress in the plastic zone can be obtained by solving Equation (31) as

$$
\left\{\begin{array}{l}
\sigma_{r d}=\left(p_{i}-\frac{N_{d}+\eta F}{1-M}\right)\left(\frac{R_{0}}{r}\right)^{1-M}+\frac{N_{d}+\eta F}{1-M}, \\
\sigma_{\theta d}=M\left(p_{i}-\frac{N_{d}+\eta F}{1-M}\right)\left(\frac{R_{0}}{r}\right)^{1-M}+\frac{M N_{d}+\eta F}{1-M} .
\end{array}\right.
$$

3.5. Radius of Postpeak Failure Zone. Because of the continuity of radial stress in the surrounding rock of the tunnel, the 
relationship between $R_{p}$ and $R_{d}$ can be established by combining with (26) and (32).

$$
\begin{aligned}
\left(\sigma_{r}^{e-p}-\frac{N_{e}+\eta F}{1-M}\right)\left(\frac{R_{p}}{R_{d}}\right)^{1-M}+\frac{N_{e}+\eta F}{1-M} & \\
& +\frac{4 \cos \varphi /(\sqrt{3}-2 \sin \varphi) \alpha\left(\varepsilon_{\theta}^{e-p}-\varepsilon_{r}^{e-p}\right)}{\left(\beta_{p}+1\right)\left(\beta_{p}+M\right)} \\
& \cdot\left[\left(\frac{R_{p}}{R_{d}}\right)^{1-\beta_{p}}-\left(\frac{R_{p}}{R_{d}}\right)^{1-M}\right] \\
& +\frac{4 \cos \varphi /(\sqrt{3}-2 \sin \varphi) \alpha\left(\varepsilon_{\theta}^{e-p}-\varepsilon_{r}^{e-p}\right)}{\left(\beta_{p}+1\right)(1-M)}\left[1-\left(\frac{R_{p}}{R_{d}}\right)^{1-M}\right] \\
= & \left(p_{i}-\frac{N_{d}+\eta F}{1-M}\right)\left(\frac{R_{0}}{R_{d}}\right)^{1-M}+\frac{N_{d}+\eta F}{1-M} .
\end{aligned}
$$

According to Equation (24), the cohesion at $r=R_{d}$ can be expressed as follows:

$$
c_{d}=c_{0}-\frac{\alpha\left(\varepsilon_{\theta}^{e-p}-\varepsilon_{r}^{e-p}\right)}{\beta_{p}+1}\left[\left(\frac{R_{p}}{R_{d}}\right)^{\beta_{p}+1}-1\right] .
$$

Subsequently, the radii $R_{p}$ and $R_{d}$ can be derived by integrating (33) and (34).

\section{Case Study}

The stress distribution and deformation of the tunnel surrounding rock are of great importance for the stability evaluation and support design of the tunnel. In order to study the influence of pore water pressure, intermediate principal stress, and residual cohesion on the stresses and displacement of the tunnel, the mechanical and geometrical parameters of the rock mass are shown in Table 1.

\subsection{Effect of Pore Water Pressure}

4.1.1. Postpeak Zone Radii and Surface Displacement. Figure 5 shows the postpeak zone radii and surface displacement around the tunnel under different pore water pressure. The radii of plastic and damage zones and surface displacement all increase with the increase of pore water pressure. For example, as $P_{0}$ increases from $3 \mathrm{MPa}$ to $6 \mathrm{MPa}$, the $R_{p}$, $R_{d}$, and $u_{0}$ values at the tunnel side increase by $0.85 \mathrm{~m}$, $0.83 \mathrm{~m}$, and $36.44 \mathrm{~mm}$, with an increment of $20.48 \%$, $22.61 \%$, and $67.31 \%$, respectively, and the $R_{p}, R_{d}$, and $u_{0}$ values at the tunnel crown increase by $0.77 \mathrm{~m}$ and $0.75 \mathrm{~m}$, and $72.06 \mathrm{~mm}$, with an increment of $13.62 \%, 14.24 \%$, and $43.43 \%$, respectively. Therefore, the pore water pressure exerts a crucial influence on the radii of plastic and damage zones and surface displacement.

4.1.2. Stress Distribution in Tunnel Surrounding Rock. Taking the tunnel crown as an example, the stress distribution based
TABLE 1: Geometrical and mechanical parameters.

\begin{tabular}{lc}
\hline Parameters & Values \\
\hline Radius of the tunnel, $R_{0}(\mathrm{~m})$ & 3 \\
Initial stress, $\sigma_{0}(\mathrm{MPa})$ & 16.2 \\
Support pressure, $P_{i}(\mathrm{MPa})$ & 0 \\
Lateral stress coefficient & 1.5 \\
Pore water pressure, $P_{0}(\mathrm{MPa})$ & 5 \\
Pore water pressure coefficient, $\eta$ & 1 \\
$R_{e} / R_{0}$ & 12 \\
Poisson's ratio, $\mu$ & 0.25 \\
Young's modulus, $E(\mathrm{MPa})$ & 2400 \\
Initial cohesion, $c_{0}(\mathrm{MPa})$ & 3.5 \\
Residual cohesion, $c_{d}(\mathrm{MPa})$ & 1.5 \\
Dilation angle, $\psi_{i}\left({ }^{\circ}\right)$ & 10 \\
\hline
\end{tabular}

on different pore water pressure is shown in Figure 6. It can be seen that the tangential stresses are always larger than the radial stress. The radial stress presents a gradually increasing trend, while the tangential stress presents a trend of first increasing and then decreasing, and the maximum tangential stress appears at the interface between the elastic and plastic zones. As the pore water pressure increases, the maximum tangential stress increases and is farther away from the center of the tunnel.

\subsection{Effect of Intermediate Principal Stress}

4.2.1. Postpeak Zone Radii and Surface Displacement. In order to research the influence of intermediate principal stress on the tunnel deformation, the current analytical results are compared with the data obtained based on the Mohr-Coulomb criterion. As shown in Figure 7, because of the neglect of the intermediate principal stress in the MohrCoulomb criterion, the $R_{p}, R_{d}$, and $u_{0}$ values solved by the Mohr-Coulomb criterion are all larger than those solved by the Mogi-Coulomb criterion. For example, the $R_{p}, R_{d}$, and $u_{0}$ values at the tunnel side from the Mogi-Coulomb criterion are $4.73 \mathrm{~m}, 4.22 \mathrm{~m}$, and $76.71 \mathrm{~mm}$, respectively; however, the results from the Mohr-Coulomb criterion are $6.83 \mathrm{~m}, 5.95 \mathrm{~m}$, and $130.69 \mathrm{~mm}$, with an increment of $44.40 \%, 40.99 \%$, and $70.37 \%$, respectively.

4.2.2. Stress Distribution in Tunnel Surrounding Rock. The stress distribution at the tunnel crown based on two different criteria is shown in Figure 8. It can be seen that the intermediate principal stress has a significant effect on the stress distribution in the three zones. When the intermediate principal stress is ignored, the stress concentration and maximum tangential stress are larger, and the boundary between the plastic and elastic zones is closer to the tunnel center.

\subsection{Effect of Residual Cohesion}

4.3.1. Postpeak Zone Radii and Surface Displacement. Figure 9 shows the postpeak zone radii and surface displacement around the tunnel under different types of residual 

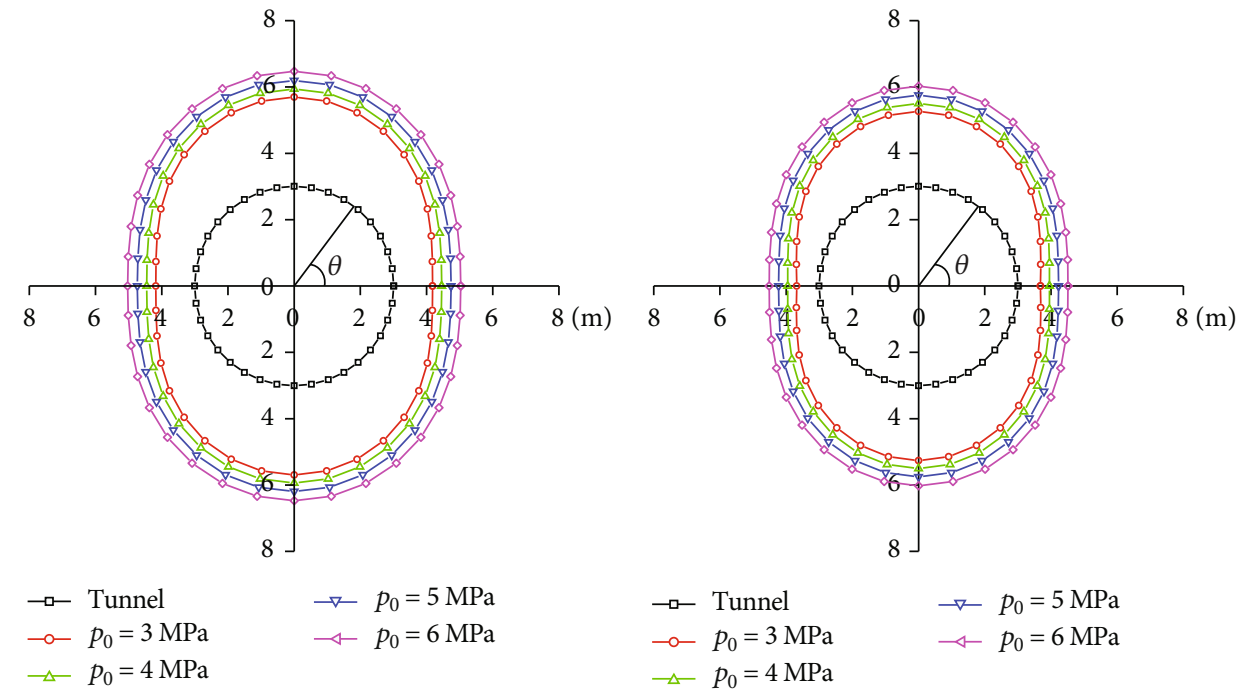

$$
\rightarrow-p_{0}=5 \mathrm{MPa}
$$

$\rightarrow-$ Tunnel

$\multimap p_{0}=3 \mathrm{MPa}$

$\rightarrow p_{0}=5 \mathrm{MPa}$

$\triangle p_{0}=4 \mathrm{MPa}$

(a) $R_{p}$

(b) $R_{d}$

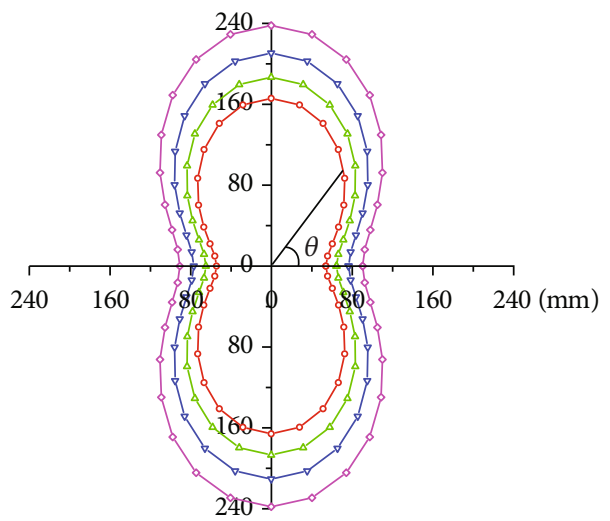

$\begin{array}{ll}\multimap p_{0}=3 \mathrm{MPa} & \rightarrow p_{0}=5 \mathrm{MPa} \\ \neg-p_{0}=4 \mathrm{MPa} & \triangleleft p_{0}=6 \mathrm{MPa}\end{array}$

(c) $u_{0}$

FIgURE 5: Postpeak zone radii and surface displacement around the tunnel under different pore water pressures.

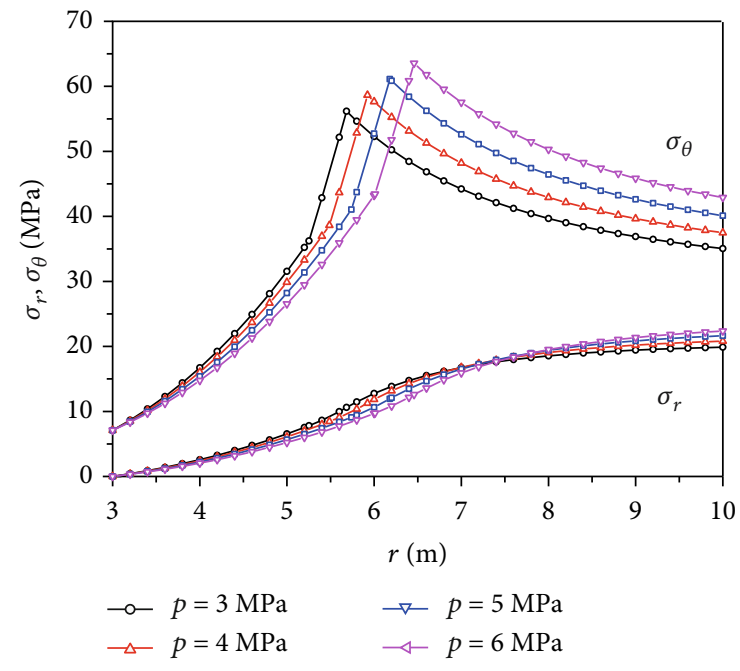

Figure 6: Comparison of stress distribution at the tunnel crown based on different pore water pressures. cohesion. The radii of plastic and damage zones and surface displacement all decrease with the increase of residual cohesion. For example, as $c_{d}$ increases from $1.5 \mathrm{MPa}$ to $2.5 \mathrm{MPa}$, the $R_{p}, R_{d}$, and $u_{0}$ values at the tunnel side decrease by $1.34 \mathrm{~m}, 0.86 \mathrm{~m}$, and $37.39 \mathrm{~mm}$, with a reduction of $24.45 \%$, $18.07 \%$, and $37.59 \%$, respectively, and the $R_{p}, R_{d}$, and $u_{0}$ values at the tunnel crown increase by $2.41 \mathrm{~m}$ and $1.94 \mathrm{~m}$, and $164.56 \mathrm{~mm}$, with a reduction of $32.01 \%, 28.24 \%$, and $52.63 \%$, respectively. Therefore, some measures, such as grouting, can be used to increase the residual cohesion of the rock mass and reduce the deformation of the tunnel.

4.3.2. Stress Distribution in Tunnel Surrounding Rock. The stress distribution based on different types of residual cohesion is shown in Figure 10. It can be seen that the radial stress is always in the increasing trend and the tangential stress is always larger than the radial stress, which are similar to those laws in Figures 6 and 9. As the residual cohesion increases, 


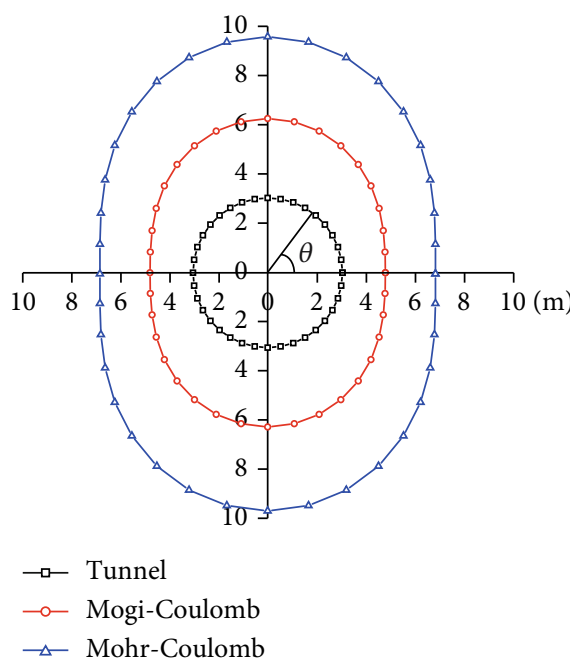

(a) $R_{p}$

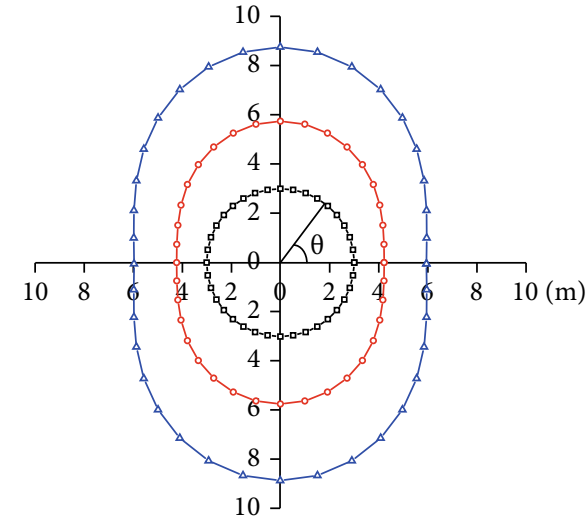

$\rightarrow$ Tunnel

$\multimap-$ Mogi-Coulomb

$\triangle$ Mohr-Coulomb

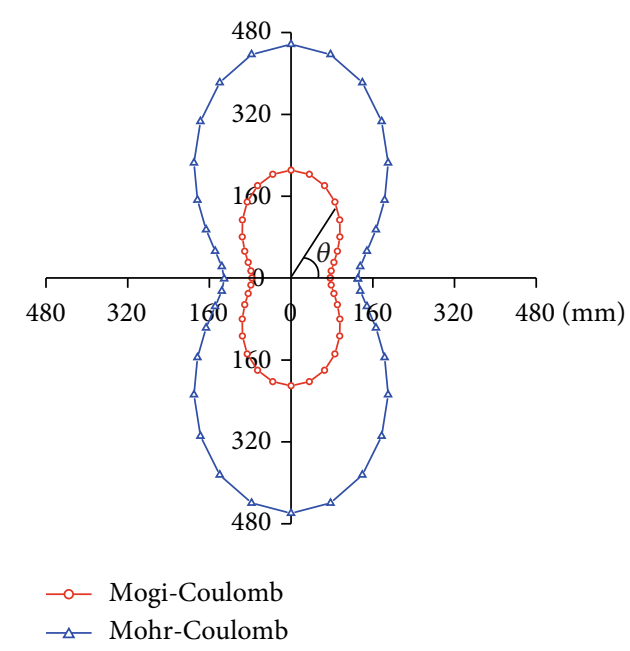

(b) $R_{d}$

(c) $u_{0}$

Figure 7: Postpeak zone radii and surface displacement around the tunnel under different strength criteria.

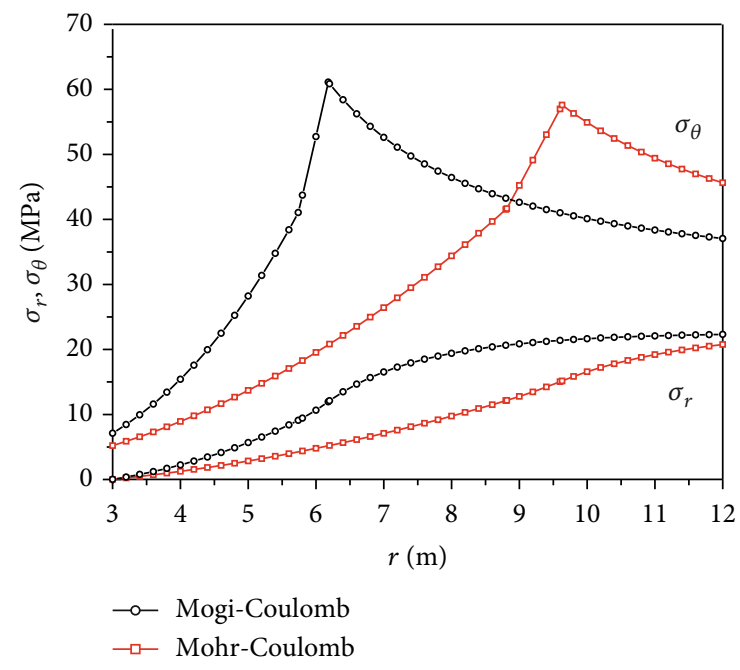

Figure 8: Comparison of stress distribution at the tunnel crown based on different strength criteria. the maximum tangential stress increases slightly, but the boundary between the plastic and elastic zones moves farther away from the center of the tunnel.

\section{Conclusions}

Considering the pore water pressure, the stress distribution and postpeak zone radii in the surrounding rock of a deep tunnel in water-rich areas are deduced based on a strainsoftening model and the Mogi-Coulomb criterion. The influence of pore water pressure, intermediate principal stress, and residual cohesion on the stress distribution and postpeak zone radii is also discussed. The conclusions can be summarized as follows:

(1) As for the stress distribution in the surrounding rock of a tunnel, the tangential stresses are always larger than the radial stress. The radial stress presents a gradually increasing trend, while the tangential stress 

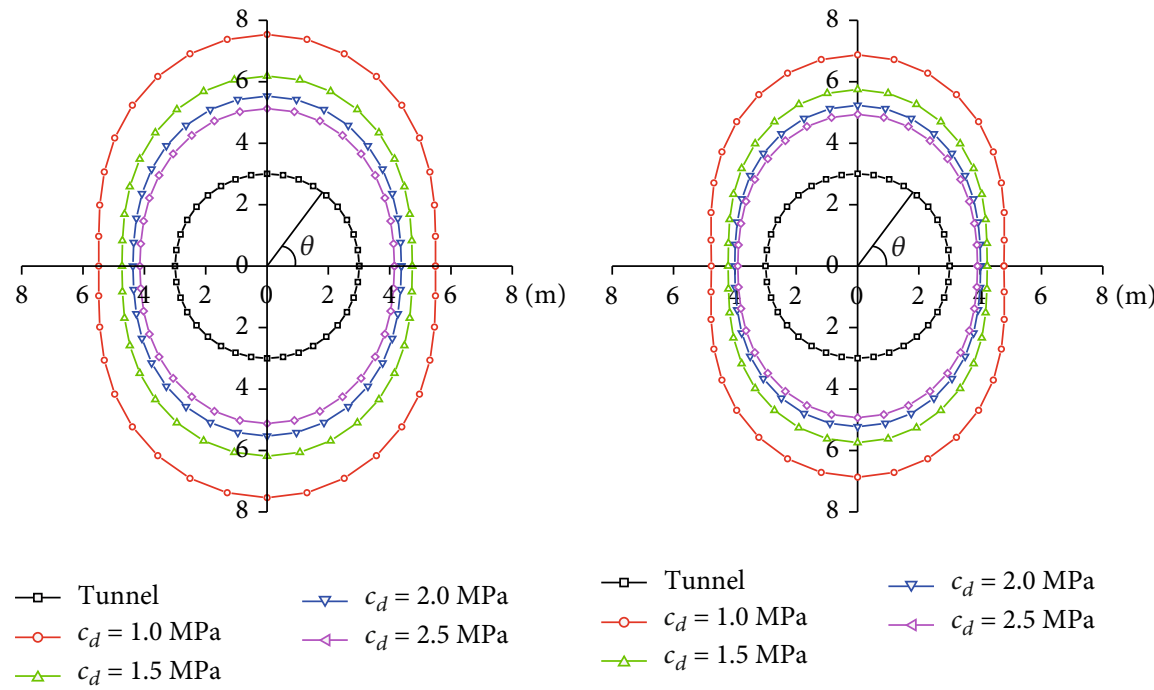

$$
\begin{aligned}
& \smile \smile c_{d}=2.0 \mathrm{MPa} \\
& \smile c_{d}=2.5 \mathrm{MPa}
\end{aligned}
$$$$
\rightarrow-\text { Tunnel }
$$$$
\multimap c_{d}=1.0 \mathrm{MPa}
$$$$
\rightarrow-c_{d}=2.0 \mathrm{MPa}
$$$$
\triangle c_{d}=1.5 \mathrm{MPa}
$$$$
\triangle c_{d}=1.5 \mathrm{MPa}
$$

(a) $R_{p}$

(b) $R_{d}$

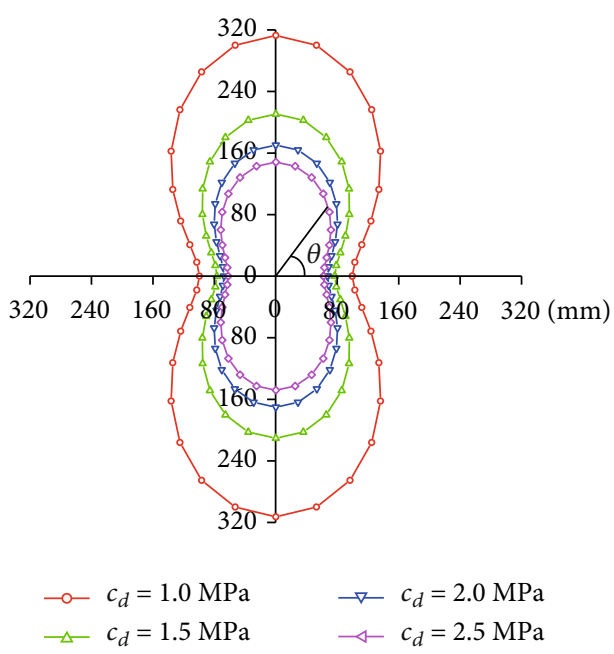

(c) $u_{0}$

FIGURE 9: Postpeak zone radii and surface displacement around the tunnel under different types of residual cohesion.

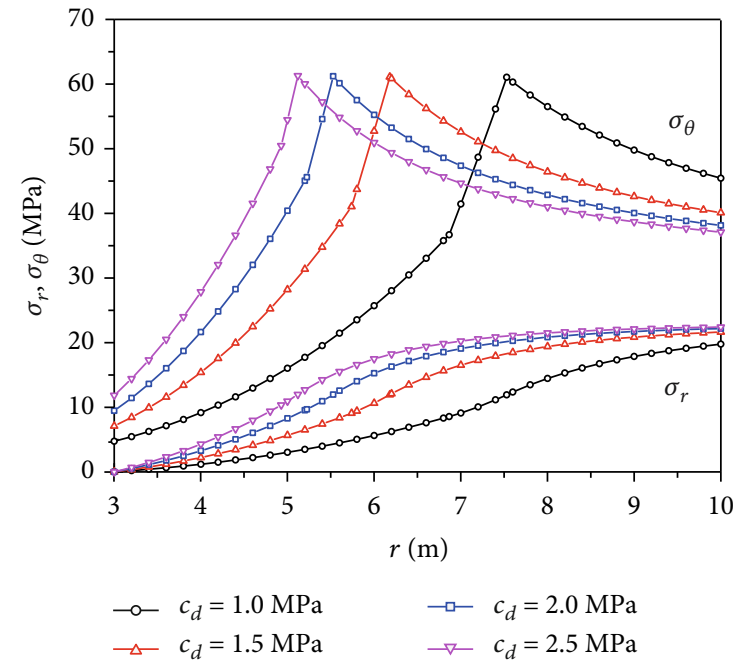

Figure 10: Comparison of stress distribution at the tunnel crown based on different types of residual cohesion. presents a trend of first increasing and then decreasing, and the maximum tangential stress appears at the interface between the elastic and plastic zones

(2) The postpeak zone radii and surface displacement increase with the increasing pore water pressure and decreasing residual cohesion. The greater the pore water pressure, the farther the maximum tangential stress is from the center of the tunnel. Residual strength has little effect on the maximum tangential stress

(3) Because of the neglect of intermediate principal stress in the Mohr-Coulomb criterion, the postpeak zone radii, surface displacement, and maximum tangential stress solved by the Mohr-Coulomb criterion are all larger than those solved by the Mogi-Coulomb criterion. Therefore, opportune consideration of the intermediate principal stress can lead to a more reasonable tunnel support design 


\section{Data Availability}

All data generated or analyzed during this study are included in this published article.

\section{Conflicts of Interest}

The authors declare that they have no conflicts of interest.

\section{Authors' Contributions}

The manuscript is approved by all authors for publication.

\section{Acknowledgments}

Financial support from the National Key Research and Development Program of China (No. 2017YFC0603004) and the China Postdoctoral Science Foundation funded project (No. 2020M671649) is gratefully acknowledged.

\section{References}

[1] B. Jiang, L. Wang, Y. Lu, S. Gu, and X. Sun, "Failure mechanism analysis and support design for deep composite soft rock roadway: a case study of the Yangcheng Coal Mine in China," Shock and Vibration, vol. 2015, Article ID 452479, 14 pages, 2015.

[2] Q. Guo, J. Pan, X. Wu, X. Xi, and M. Cai, "A new unified solution for circular tunnels based on generalized SMP criterion considering the strain softening and dilatancy," Advances in Civil Engineering, vol. 2019, Article ID 1684707, 10 pages, 2019.

[3] H. Fan, L. Wang, and W. Liu, "An analytical solution for stresses and deformations of tunnels in a non-uniform stress field based on strain-softening model and Mogi-Coulomb criterion," Latin American Journal of Solids and Structures, vol. 17, no. 1, pp. 1-16, 2020.

[4] Y. Xue, P. G. Ranjith, F. Dang et al., "Analysis of deformation, permeability and energy evolution characteristics of coal mass around borehole after excavation," Natural Resources Research, vol. 29, no. 5, pp. 3159-3177, 2020.

[5] Q. Zhang, B. S. Jiang, X. S. Wu, H. Q. Zhang, and L. J. Han, "Elasto-plastic coupling analysis of circular openings in elasto-brittle-plastic rock mass," Theoretical and Applied Fracture Mechanics, vol. 60, no. 1, pp. 60-67, 2012.

[6] B. Jiang, Q. Zhang, Y. He, and L. Han, "Elastioplastic analysis of cracked surrounding rocks in deep circular openings," Chinese Journal of Rock Mechanics and Engineering, vol. 26, pp. 982-986, 2007.

[7] K. Park and Y. Kim, "Analytical solution for a circular opening in an elastic-brittle-plastic rock," International Journal of Rock Mechanics and Mining Sciences, vol. 43, no. 4, pp. 616-622, 2006.

[8] Y. K. Lee and S. Pietruszczak, "A new numerical procedure for elasto-plastic analysis of a circular opening excavated in a strain-softening rock mass," Tunnelling and Underground Space Technology, vol. 23, no. 5, pp. 588-599, 2008.

[9] L. R. Alejano, A. Rodriguez-Dono, E. Alonso, and G. FdezManín, "Ground reaction curves for tunnels excavated in different quality rock masses showing several types of postfailure behaviour," Tunnelling and Underground Space Technology, vol. 24, no. 6, pp. 689-705, 2009.
[10] R. Z. Mohammad and F. Ahmad, "Elastic-brittle-plastic analysis of circular deep underwater cavities in a Mohr-Coulomb rock mass considering seepage forces," International Journal of Geomechanics, vol. 15, pp. 1-10, 2015.

[11] S. K. Sharan, "Elastic-brittle-plastic analysis of circular openings in Hoek-Brown media," International Journal of Rock Mechanics and Mining Science, vol. 40, no. 6, pp. 817-824, 2003.

[12] S. K. Sharan, "Exact and approximate solutions for displacements around circular openings in elastic-brittle-plastic Hoek-Brown rock," International Journal of Rock Mechanics and Mining Sciences, vol. 42, no. 4, pp. 542-549, 2005.

[13] L. R. Alejano, E. Alonso, A. Rodríguez-Dono, and G. Fernández-Manín, "Application of the convergenceconfinement method to tunnels in rock masses exhibiting Hoek-Brown strain-softening behaviour," International Journal of Rock Mechanics and Mining Sciences, vol. 47, no. 1, pp. 150-160, 2010.

[14] R. Chen and F. Tonon, "Closed-form solutions for a circular tunnel in elastic-brittle-plastic ground with the original and generalized Hoek-Brown failure criteria," Rock Mechanics and Rock Engineering, vol. 44, no. 2, pp. 169-178, 2011.

[15] Z. Li, L. Wang, Y. Lu, W. Li, K. Wang, and H. Fan, "Experimental investigation on true triaxial deformation and progressive damage behaviour of sandstone," Scientific Reports, vol. 9, no. 1, pp. 3386-3404, 2019.

[16] Y. Xue, T. Teng, F. Dang, Z. Ma, S. Wang, and H. Xue, "Productivity analysis of fractured wells in reservoir of hydrogen and carbon based on dual-porosity medium model," International Journal of Hydrogen Energy, vol. 45, no. 39, pp. 20240-20249, 2020.

[17] L. A. Galin, "Plane elastic-plastic problem: plastic regions around circular holes in plates and beams," Prikladnaia Matematika i Mechanika, vol. 10, pp. 365-386, 1946.

[18] E. Detournay, “An approximate statical solution of the elastoplastic interface for the problem of Galin with a cohesivefrictional material," International Journal of Solids and Structures, vol. 22, no. 12, pp. 1435-1454, 1986.

[19] E. Detournay and C. Fairhurst, "Two-dimensional elastoplastic analysis of a long, cylindrical cavity under nonhydrostatic loading," International Journal of Rock Mechanics and Mining Science and Geomechanics Abstracts, vol. 24, no. 4, pp. 197-211, 1987.

[20] E. Detournay and C. S. John, "Design charts for a deep circular tunnel under non-uniform loading," Rock Mechanics and Rock Engineering, vol. 21, no. 2, pp. 119-137, 1988.

[21] G. Tokar, "Generalization of Galin's problem to frictional materials and discontinuous stress fields," International Journal of Solids and Structures, vol. 26, no. 2, pp. 129-147, 1990.

[22] M. J. Leitman and P. Villaggio, "Plastic zone around circular holes," Journal of Engineering Mechanics, vol. 135, no. 12, pp. 1467-1471, 2009.

[23] W. Ochensberger, C. C. Celigoj, and M. H. Ulz, "Amendment to the Galin plane elastoplastic solution," Journal of Engineering Mechanics, vol. 139, no. 11, pp. 1658-1662, 2013.

[24] X. Li, S. Du, and B. Chen, "Unified analytical solution for deep circular tunnel with consideration of seepage pressure, grouting and lining," Journal of Central South University, vol. 24, no. 6, pp. 1483-1493, 2017.

[25] J. Pan, Q. Guo, F. Ren, and M. Cai, "Comparative analysis of different strength criteria for deep-buried rock roadway under 
seepage," Journal of China Coal Society, vol. 44, no. 11, pp. 3369-3378, 2019.

[26] Y. J. Shin, B. M. Kim, J. H. Shin, and I. M. Lee, “The ground reaction curve of underwater tunnels considering seepage forces," Tunnelling and Underground Space Technology, vol. 25, no. 4, pp. 315-324, 2010.

[27] K. Mogi, "Effect of the intermediate principal stress on rock failure," Journal of Geophysical Research, vol. 72, no. 20, pp. 5117-5131, 1967.

[28] K. Mogi, "Fracture and flow of rocks under high triaxial compression," Journal of Geophysical Research, vol. 76, no. 5, pp. 1255-1269, 1971.

[29] B. C. Haimson and C. Chang, "A new true triaxial cell for testing mechanical properties of rock, and its use to determine rock strength and deformability of Westerly granite," International Journal of Rock Mechanics and Mining Sciences, vol. 37, no. 1-2, pp. 285-296, 2000. 